\title{
INTEGRASI BUDAYA DALAM PENDIDIKAN AKUNTANSI UNTUK MENCAPAI KEUNGGULAN KOMPETITIF LULUSAN
}

\author{
Nurafni Eltivia1 \\ Politeknik Negeri Malang \\ nurafni.eltivia@polinema.ac.id \\ Hesti Wahyuni ${ }^{3}$ \\ Politeknik Negeri Malang \\ wahyunihesti@yahoo.com
}

\author{
Kurnia Ekasari² \\ Politeknik Negeri Malang \\ kurnia.es@gmail.com \\ Elvyra Handayani Soedarso ${ }^{4}$ \\ Politeknik Negeri Malang \\ elvirasoedarso@gmail.com
}

\begin{abstract}
ABSTRAK
Penelitian ini bertujuan untuk mengeksplorasi betapa budaya dapat menjadi alat diferensiasi bagi akuntan untuk mencapai keunggulan kompetitif. Hermeneutik digunakan sebagai alat analisis dalam penelitian untuk mencari nilai luhur yang terdapat dalam filosofi suatu budaya. Filosofi Sedulur Papat Kalimo Pancer (Jawa), Siri na Pacce (Bugis-Makassar), dan Tri Hita Karana (Bali) akan dieksplorasi dalam penelitian ini. Hasil penelitian ini menunjukkan bahwa budaya lokal tersebut memiliki nilai luhur yang bila diinternalisasi dalam pendidikan Akuntansi, akan dapat membawa Akuntan Indonesia memiliki keunggulan kompetitif dalam persaingan global. Nilai-nilai diferensiasi tersebut adalah tersebut adalah Ketuhanan, sinergi dan harmonisasi, dan etos kerja.
\end{abstract}

Kata Kunci : Pendidikan Akuntansi; Budaya; Diferensiasi; Keunggulan Kompetitif

\begin{abstract}
This study attempts to explore how culture can be differentiation instrumental for an accountant to achieve competitive advantage. Hermeneutics will be used to solicit the virtue values of the culture philosophy. Sedulur papat kalimo pancer (Javaneese), Siri na Pacce (Bugis-Makassar), and Tri Hita Karana (Balineese) will be explored in this research. The results of this study indicate that local culture has noble values which, when internalized in Accounting Education will be able to bring competitive advantage in the global competition. Those differentiation value are divinity, synergy and harmonization, and work ethic.
\end{abstract}

Keywords: accounting education; culture; differentiation; competitive advantage

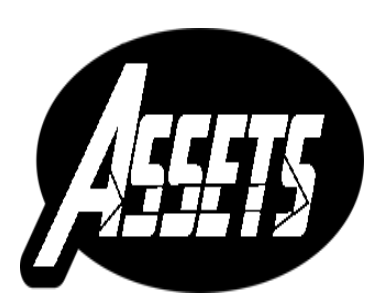

ASSETS

Jurnal Akuntansi dan Pendidikan

Vol. 8 No. 2

Hlmn. 138-145

Madiun, Oktober 2019

p-ISSN: 2302-6251

e-ISSN: 2477-4995

Artikel masuk: 26 Maret 2019 Tanggal diterima: 19 September 2019 


\section{PENDAHULUAN}

Profesi akuntan termasuk dalam Mutual Recognition Arrangement (MRA) sebagai profesi yang diakui di area ASEAN. Sebagai profesi yang turut dalam MRA tentunya menjadi peluang sekaligus tantangan bagi dunia Pendidikan Akuntansi di Indonesia untuk memenangkan persaingan di pasar tenaga kerja. Lebih lanjut, area persaingan bebas di masa yang akan datang tentunya akan semakin luas, tidak hanya area ASEAN lagi. Pendidikan akuntansi di Indonesia perlu mempersiapkan diri untuk menjawab tantangan tersebut agar lulusannya mampu memenangkan persaingan. Salah satu strategi untuk memiliki keunggulan, dan memenangkan persaingan adalah dengan melakukan diferensiasi kurikulum pendidikan.

Terdapat beberapa strategi yang digunakan untuk meningkatkan keunggulan kompetitif (Wen-Cheng, Chien-Hung, \& Ying-Chien, 2011). Lebih lanjut menurut WenCheng et al (2011), diferensiasi merupakan strategi yang digunakan bila berada dalam pasar dan segmen yang luas. Strategi ini dapat digunakan dalam berbagai lini seperti untuk produk, perusahaan (Al-alak \& Tarabieh, 2011). Diferensiasi merupakan salah satu strategi yang dapat dilakukan dengan cara menciptakan keunikan, sebagaimana dinyatakan oleh Storper (2009: 4) bahwa perbedaan kondisi sosio ekonomi dari suatu organisasi adalah merupakan kunci penting untuk melakukan kreasi. Diferensiasi atau pembeda bisa diciptakan atau sebaliknya tidak perlu diciptakan karena sudah tertanam misalnya budaya lokal. Budaya lokal dapat menjadi modal untuk melakukan diferensiasi karena budaya lokal biasanya bersifat unik dan otentik.

Lee (2008) menyatakan terdapat premis mengenai interaksi manusia yang dapat direduksi menjadi tiga elemen dasar yaitu pertukaran, otoritas dan jaringan. China dan Jepang telah memiliki comparative advantage (Nakagane, 2017). Hal ini tidak dapat dilepaskan dari bagaimana mereka melakukan interaksi yang telah tertanam dalam budayanya masing-masing. Budaya China sudah terkenal dengan budaya kerja keras dan pantang menyerah, Jepang sudah terkenal dengan budaya etos kerja dan integritasnya.

Kearifan lokal menurut Dahliani, Soemarno, \& Setijanti (2015) berasal dari daya pikir manusia yang akan menyesuaikan keberadaannya di lingkungan alami yang dapat dimanifestasikan dalam karya-karyanya secara nyata sebagai lingkungan terbangun dan tidak berwujud. Lebih lanjut, Dahliani et al., (2015) juga menyatakan bahwa kearifan lokal selalu berubah, karena mengikuti dinamika budaya dan tidak dapat dipisahkan dari pola pikir manusia.

Lantas bagaimana dengan Indonesia dalam persaingan global, khususnya bagi profesi akuntan? Perlu dirumuskan nilai-nilai apa yang dapat diinternalisasi dalam Pendidikan Akuntansi untuk mewujudkan diferensiasi tersebut. Indonesia dengan budaya tradisionalnya yang majemuk pasti memiliki kearifan lokal dan nilai-nilai yang dapat diinternalisasi untuk menciptakan diferensiasi. Penelitian terdahulu yang menggali kearifan lokal budaya dihubungkan dengan karakter akuntan (Eltivia, 2013; 2015). Namun budaya yang digunakan barulah budaya Jawa khususnya Jawa Timur.

Penelitian ini berusaha untuk mencari nilai-nilai tersebut dengan menggunakan tiga budaya yaitu Budaya Jawa, Bugis-Makassar dan Bali. Indonesia memiliki beberapa pulau besar, dan tiga budaya tersebut dipilih karena berada dalam wilayah tiga pulau besar yang berbeda. Tentunya hal ini memberikan dampak perbedaan cukup besar dalam hal budaya seperti filosofi, bahasa, pakaian adat, ritual keagamaannya, adat istiadat. Sehingga diharapkan dapat mewakili keanekaragaman budaya di Indonesia. Pulau Jawa sendiri terbagi mejadi Jawa Barat, Jawa Tengah dan Jawa Timur. Antara budaya Jawa Timur dengan Jawa Tengah relatif lebih menyerupai dibanding dengan Jawa Barat, namun menurut data (BPS, n.d.) jumlah penduduk di Jawa Timur lebih 
besar dibanding Jawa Tengah. Penelitian ini akan mengeksplorasi budaya Jawa Timur (namun dalam penelitian ini akan tetap disebut sebagai budaya Jawa).

\section{METODE PENELITIAN}

Penelitian ini adalah penelitian kualitatif dengan menggunakan phenomenology hermeneutic sebagai alat analisis. Umiarso (2011: 193) menyatakan bahwa hermeneutik adalah suatu proses mengubah dari ketidaktahuan menjadi tahu. Lebih lanjut, istilah hermeneutika (hermeneutic) berasal dari Yunani, hermeneuein yang secara etimologi artinya adalah menerjemahkan atau menafsirkan. Hermeneutika secara sederhana dapat diartikan sebagai interpretasi tekstual, atau, menemukan makna. Sedangkan phenomenology hermeneutic adalah suatu pendekatan interdisciplinary yang berasal dari berbagai disiplin dan memiliki serangkaian prinsip mendasar yang digunakan untuk memperoleh pemahaman akan suatu fenomena (Kafle, 2013).

Boell \& Cecez-Kecmanovic (2014) menyatakan bahwa terdapat dua tahap utama dalam hermeneutik sebagaimana digambarkan dalam Gambar 1. Yang pertama adalah search and acquisition, selanjutnya adalah analysis and interpretation. Pada tahap pertama, search and acquisition akan dieksplorasi dan dipilih budaya lokal mana yang akan dianalisis. Selain itu, literatur-literatur terkait budaya lokal juga dibaca, diidentifikasi dan pada akhirnya dipilih untuk digunakan pada tahap analysis and interpretation.



\section{Gambar 1. Dua Tahapan Utama dalam Hermeneutik}

Sumber: Boell \& Cecez-Kecmanovic (2014)

Penelitian ini dilakukan pada budaya Jawa, Bugis-Makasar dan Bali. Ketiga budaya tersebut mewakili 3 pulau besar di Indonesia. Selanjutnya tiga filosofi budaya yang dipilih adalah Sedulur Papat Kalimo Pancer (Jawa), Siri na Pacce (Bugis- Makasar), dan Tri Hita Karana (Bali). Ketiga filosofi tersebut dipilih karena berdasarkan proses search and acquisition dapat menggambarkan bagaimana kriteria pribadi yang unggul dan perlu dibentuk pada Pendidikan Akuntansi. Filosofi yang telah dipilih, akan digali maknanya untuk mengumpulkan nilai-nilai yang dapat digunakan sebagai instrumen diferensiasi dalam Pendidikan Akuntansi di Indonesia. Sedangkan penggalian makna akan filosofi tersebut dengan menggunakan penelitian Eltivia $(2013 ; 2015)$. 


\section{HASIL PENELITIAN DAN PEMBAHASAN}

Pada bagian ini, masing-masing filosofi akan dibahas satu-persatu untuk mendapatkan nilai-nilai yang akan membentuk akuntan menjadi pribadi yang unggul. Budaya Jawa: Sedulur Papat Kalimo Pancer

Budaya Jawa memiliki filosofi yang luhur yaitu sedulur papat kalimo pancer. Seperti dinyatakan Eltivia (2013), terdapat lima elemen dasar pada filosofi ini terkait sedulur yang tidak nyata namun mengiringi manusia sejak lahir hingga menutup mata. Sedulur tersebut adalah Watman, Wahman, Rahman, Ariman. Watman adalah jelmaan sedulur tertua, yang harus dihormati. Wahman merupakan saudara yang melindungi dan menjaga. Rahman adalah saudara yang senantiasa memberi semangat dalam mengarungi kehidupan. Ariman merupakan saudara yang menolong manusia untuk dapat mencari nafkah dan memelihara kehidupan.

Selanjutnya sedulur papat kalimo pancer bila dikaitkan dengan kegiatan dalam keseharian, maka dirasa perlu untuk memiliki cipta, rasa, karsa dan karya (Eltivia, 2013). Lebih lanjut Eltivia (2013) menyatakan, cipta akan dimiliki oleh pikiran yang jernih dan dapat membimbing dalam menyelesaikan pekerjaan dan permasalahan yang terjadi dengan tepat.

Adanya "rasa" akan membantu dalam bekerjasama dengan pihak lain. Rasa dimunculkan dengan adanya ketulusan hati, yang dirasakan secara langsung oleh pihak lain. Ketulusan menurut Eltivia (2015) akan mendorong akuntan untuk bekerja tanpa pamrih dan terhindar dari potensi menjadi pribadi oportunis, individualis, matrealistis, dan kapitalistis. Selanjutnya "Karsa" yang berarti kekuatan niat dan tekad seseorang, menurut Eltivia (2015) akan menjadikan seseorang pribadi yang tangguh. Seseorang juga sepatutnya untuk ber-karya. Karya menurut Eltivia (2015) adalah keinginan dan kemampuan untuk bertindak nyata.

Cipta, rasa, karsa, dan karya yang menjadi pengejawantahan aspek sedulur papat kalimo pancer dalam filosofi Jawa, keempat-keempatnya dibutuhkan dalam membentuk karakter. Namun keempat aspek ini belum lengkap bila tidak ditambah dengan adanya "pancer" yaitu kesadaran (Eltivia, 2015). Lebih lanjut, Eltivia (2015) menyatakan bahwa pribadi yang unggul dapat dibentuk ketika telah memiliki keempat element tersebut dan dilengkapi dengan "kesadaran". Gambar 2 menunjukkan relasi cipta, rasa, karsa dan karya dalam perilaku manusia :

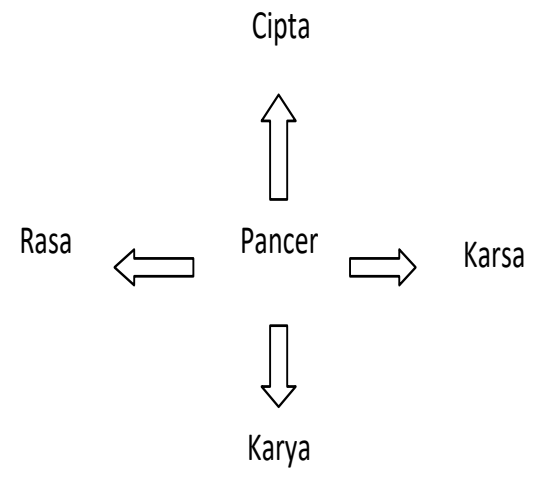

\section{Gambar 2. Sedulur Papat Kalimo Pancer dalam Perilaku Manusia}

\section{Budaya Bugis- Makasar: Siri Na Pacce}

Bugis- Makasar memiliki filosofi Siri' $\mathrm{Na}$ Pacce., yang secara harfiah menurut Rahayu, Suhaeb, Sulkarnain, Anrisal, \& Satnawati (2018), 'siri' berarti harga diri atau kehormatan atau reputasi, tetapi sebagai konsep sosial budaya itu memiliki dua makna. Pertama, siri thilakasiri' adalah perasaan malu yang mendalam ketika martabat 
seseorang telah terdegradasi oleh orang lain di depan umum. Kedua, 'siri ma siri' adalah cara hidup yang mengarahkan semangat seseorang untuk mendapatkan kesuksesan. Selanjutnya menurut Magfirah (2016) menyatakan adanya integrasi siri dalam kehidupan beragama terungkap dalam pesan atau filsafat berikut:

Tellui ri ala sappo Tau'e ri dewata Siri; -'e ri watakkale Siri'e ri padatta tau

Yang memiliki arti bahwa terdapat tiga prinsip yaitu beriman (percaya) kepada Tuhan, menghormati dan menghargai diri sendiri, dan menghargai menghormati manusia lainnya. Menurut filosofi siri, terdapat lima prinsip perilaku (Said, 2004). Pertama adalah Ada Tongeng (berkata kebenaran). Ada tongeng adalah suatu prinsip dalam berkata-kata haruslah menyampaikan kebenaran. Kebenaran yang disampaikan tentunya berlandaskan kejujuran. Lebih lanjut, setiap kata-kata yang diucapkan diharapkan memberikan kebaikan dalam kehidupan. Seseorang sebaiknya menghindari mengucapkan kata yang menyakiti seseorang atau suatu kelompok. Selanjutnya, adalah Lempuk (kejujuran). Lempuk adalah prinsip yang digunakan seseorang untuk selalu bertindak atas dasar kebenaran, dan menghindari untuk melakukan sesuatu yang tidak benar. Berikutnya aadalah Getteng atau yang artinya keteguhan. Getteng adalah bagaimana berperilaku dan bersikap secara jelas dan teguh terhadap suatu hal. Mempertahankan sesuatu yang dipercayai benar adalah suatu keharusan. Prinsip berikutnya adalah Sipakatau yang artinya saling menghormati. Sipakatau adalah prinsip berkomunikasi satu sama lain dengan baik. Setiap orang memiliki perbedaan namun perbedaan tersebut tetap dihormati. Hal tersebut karena setiap orang memiliki sisi rasional dan emosional yang patut dipertimbangkan. Prinsip terakhir adalah Mappesona ri dewata seuwae yaitu berserah diri kepada Tuhan. Mappesona ri dewata adalah prinsip religiusitas dimana setiap umat manusia sepatutnya berserah diri kepada Tuhan YME. Lebih lanjut, prinsip ini menyiratkan bahwa manusia harus melabuhkan setiap hal dalam hidupnya pada kehendak Tuhan YME.

\section{Budaya Bali: Tri Hita Karana}

Filosofi Tri Hita Karana (THK) berasal dari kitab suci Baghawad Gita yang merupakan bahasa Sanskerta. Tri Hita Karana (THK) merupakan hubungan yang harmonis antara tiga elemen agar umat manusia dapat mencapai kebahagiaan/kesejahteraan (Riana, 2013). Filosofi THK ini tercermin keseharian dan tata kehidupan sosial masyarakat Hindu. Tiga elemen yang terkait adalah, Parahyangan, Pawongan dan Palemahan. Parahyangan merupakan tempat suci ( Pura ) yang menggambarkan aspek Ketuhanan dalam budaya Hindu. Selanjutnya, Pawongan, merupakan tempat masyarakat bersosialisasi yang mencerminkan hubungan unsur antara sesama manusia. Sedangkan Palemahan merupakan perwujudan manusia dalam menjaga harmanisasi dengan alam lingkungan.

THK tidak hanya menjadi filosofi, melainkan telah menjadi way of life masyarakat Bali yang meyakini akan dapat meraih kebahagiaan jika kehidupannya seimbang dan harmonis melalui parahyangan, pawongan, dan palemahan. Penerapan THK dalam kehidupan mengenai hubungan antara manusia kepada Tuhannya dengan Dewa Yadnya, hubungan manusia kepada guru atau pendeta dengan Rsi Yadnya, hubungan manusia dengan alam lingkungannya yang diwujudkan dengan Bhuta Yadnya, hubungan manusia kepada leluhurnya diwujudkan dengan Pitra Yadnya, dan hubungan antara manusia dengan sesamanya diwujudkan dengan Manusia Yadnya. Apabila digambarkan, relasi antara lima yadnya tersebut adalah sebagaimana gambar 3. 


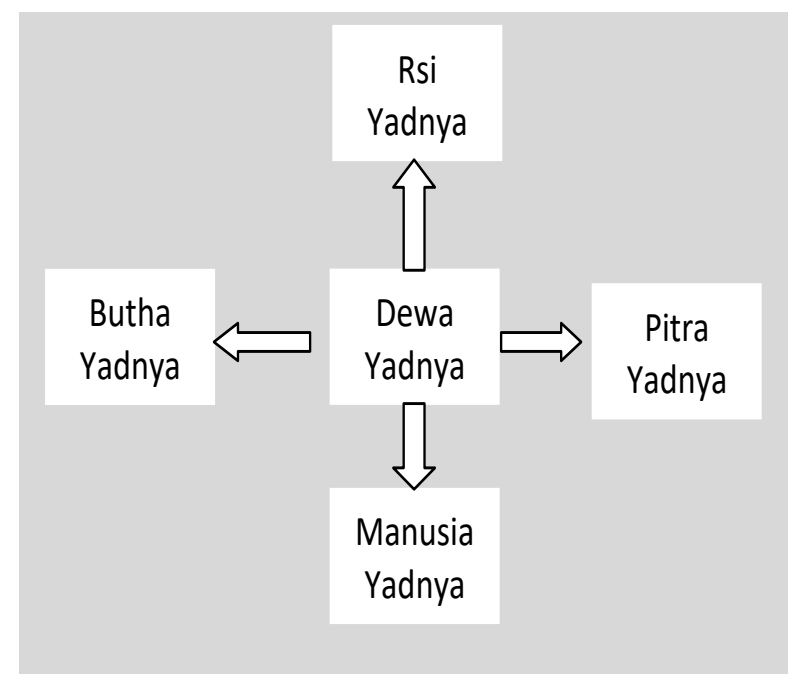

\section{Gambar 3. Yadnya dalam Budaya Bali}

\section{Nilai Budaya Lokal untuk Mencapai Keunggulan Kompetitif}

Akuntan Indonesia mengacu pada Kode Etik Akuntan yang menetapkan beberapa prinsip dasar etika dan standar akuntan agar dapat profesional di sektor publik atau sektor bisnis. Beberapa prinsip dasar etika tersebut meliputi integritas, objektivitas, kompetensi dan kehati-hatian profesional, serta perilaku profesional

Salah satu nilai penting yang bisa kita temukan pada ketiga budaya ini adalah etos kerja, hal ini nampak pada filosofi sedulur papat kalimo pancer dengan cipta, rasa, karsa dan karya. Betapa luhur bila nilai-nilai ini diterapkan dalam Pendidikan Akuntansi, terlebih bila dilengkapi dengan pancer. Niscaya akuntan Indonesia akan menjadi pribadi yang memiliki keunggulan kompetitif karena memenuhi prinsip dasar etika dan tanggungjawab akuntan baik di sektor publik atau bisnis. Budaya BugisMakassar siri na pacce juga bermuatan nilai-nilai terkait etos kerja. Bagaimana teguh memegang kebenaran dan kejujuran merupakan nilai yang saat ini semakin langka. Kebanyakan yang terjadi saat ini ketika tindak kejahatan dan korupsi makin marak, orang takut untuk menjadi berbeda untuk bertindak jujur dan benar. Akuntan yang dituntut berintegritas dan selalu independen dalam menyampaikan informasi, tentu sangat sesuai bila menerapkan Ada Tongeng, Lempuk dan Getteng. Nilai-nilai ini perlu diterapkan dalam Pendidikan Akuntansi untuk mewujudkan karakter Akuntan yang independen dan berintegritas.

Akuntan tidak akan pernah lepas dari realitas sekitarnya, termasuk dalam hal ini adalah budaya. Kearifan lokal budaya Indonesia merupakan pembeda bangsa Indonesia dengan negara lain.. Setiap filosofi budaya yang ada selalu menyampaikan betapa pentingnya untuk melakukan sinergi dan harmonisasi. Hal ini nampak jelas pada filosofi THK, bagaimana ketiga elemen yaitu ketuhanan, sesama manusia dan alam sekitar begitu ditekankan. Terlebih diperjelas dengan konsep yadnya, menunjukkan betapa pentingnya menjaga harmonisasi terhadap Tuhan, guru atau pendeta, leluhur, sesama manusia alam dan lingkungannya. Filosofi sedulur papat kalimo pancer juga menuturkan bagaimana manusia patut meniru para sedulur Watman, Wahman, Rahman, Ariman yang selalu bersinergi dalam menjaga dan melindungi manusia sejak lahir hingga menutup mata. Siri na pacce dari Bugis-Makassar juga mengajarkan manusia untuk melakukan harmoni dan sinergi melalui sipakatau atau saling menghormati. Setiap manusi perlu saling menghormati, agar terjadi sinergi dan harmonisasi. 
Nilai terakhir yang dapat ditemukan adalah terkait Ketuhanan. Ketiga filosofi budaya dalam penelitian ini memiliki beberapa kesamaan yaitu berlandaskan pada spiritualitas. Adanya dewa yadnya dan parahyangan dalam filosofi THK pada budaya Bali, menunjukkan bahwa filosofi ini memiliki landasan Ketuhanan. Sedangkan pada budaya Bugis Makasar siri na pace menunjukkan pentingnya untuk beriman kepada sang khalik dan bahwa meskipun telah mengerahkan segala daya upaya, namun pada akhirnya manusia wajib menyerahkan diri pada Tuhan YME. Budaya Jawa juga menunjukkan religiusitasnya pada konsep sedulur papat kalimo pancer. Pancer merupakan kesadaran manusia yang menunjukkan bahwa manusia patut sadar adanya kekuatan lain diluar manusia.

Nilai-nilai budaya Indonesia yang dapat dikumpulkan dan dimaknai untuk mengembangkan Pendidikan Akuntansi Indonesia sehingga Akuntan Indonesia dapat memiliki perbedaan atau diferensiasi. Bagaimana nilai Ketuhanan, sinergi dan harmonisasi, serta etos kerja amatlah ditekankan dalam budaya Indonesia. Ketika ketiga-tiganya diterapkan secara simultan tentunya akan dapat menciptakan pribadi Akuntan menjadi pribadi yang unggul karena memiliki diferensiasi. Hal ini karena nilai-nilai yang telah dikemukakan di atas sangatlah unik dan berbeda.

Aplikasi nilai-nilai tersebut tentunya secara implisit maupun eksplisit dalam kurikulum Pendidikan Tinggi Akuntansi. Secara eksplisit dituangkan dalam capaian pembelajaran dalam kurikulum dibagian sikap, sedangkan secara implisit nilai-nilai tersebut tertanam dalam setiap mata kuliah yang diberikan.

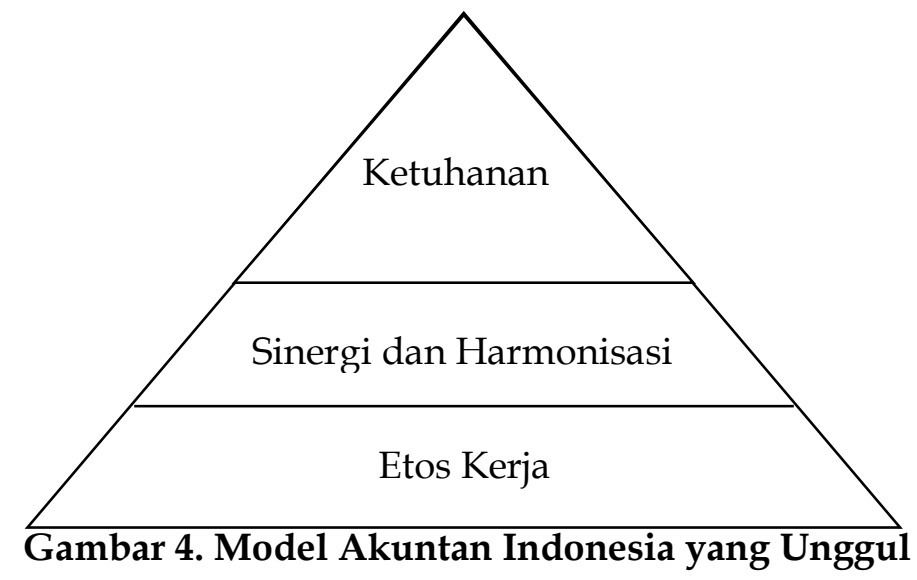

\section{SIMPULAN}

Penelitian ini menunjukkan bahwa filosofi yang terkandung dalam budaya lokal Indonesia sangatlah luhur. Bila diterapkan akan mampu mendukung pendidikan Akuntansi untuk menciptakan Akuntan yang memiliki keunggulan kompetitif melalui diferensiasi strategi. Nilai-nilai tersebut adalah Ketuhanan, sinergi dan harmonisasi, dan etos kerja yang perlu diinternalisasi dalam pendidikan Akuntansi di Indonesia

Penelitian ini memiliki keterbatasan, budaya yang diteliti hanyalah tiga budaya yaitu Jawa, Bugis-Makassar, dan Bali. Padahal Indonesia sangat kaya dengan budaya, karena memiliki banyak suku. Selanjutnya, dari masing-masing budaya tersebut hanya satu filosofi yang digunakan dan dikembangkan untuk memperoleh makna akan nilainilai luhur yang digunakan. Padahal dari masing-masing budaya tersebut banyak filosofi lain yang dimiliki.

Penelitian selanjutnya diharapkan dapat melanjutkan perjuangan dari peneliti untuk memasukan aspek budaya dalam pendidikan akuntansi. Hal ini dilakukan 
dengan mengembangkan penelitian kearah pengembangan dalam penggunaan budaya-budaya lainnya, atau kearah aplikasi budaya dalam Pendidikan Akuntansi.

\section{DAFTAR PUSTAKA}

Al-alak, B. A., \& Tarabieh, S. (M. Z. A. (2011). Gaining Competitive Advantage and Organizational Performance Through Customer Orientation, Innovation Differentiation and Market Differentiation. International Journal of Economics and Management Sciences, 1(5), 80-91.

Boell, S. K., \& Cecez-Kecmanovic, D. (2014). A hermeneutic approach for conducting literature reviews and literature searches. Communications of the Association for Information Systems, 34(1), 257-286.

BPS. (n.d.). Jumlah Penduduk Menurut Provinsi di Indonesia, 2012 - 2017 (Ribu Jiwa). Retrieved June 6, 2019, from https://jatim.bps.go.id/dynamictable/2018/03/08/371/jumlah-pendudukmenurut-provinsi-di-indonesia-2012---2017-ribu-jiwa-.html

Dahliani, D., Soemarno, I., \& Setijanti, P. (2015). Local wisdom in built environment in globalization era. International Journal of Education and Research, 3(6), 157-166.

Eltivia, N. (2013). Menguak "Pancer" Integritas Akuntan dengan Filosofi Jawa. Jurnal Riset Akuntansi Dan Keuangan, 1(3), 173-180. Retrieved from http://ejournal.upi.edu/index.php/JRAK/article/view/6695

Eltivia, N. (2015). Internalisasi “Pancer" Dalam Jiwa Akuntan: Upaya Revolusi Perilaku Akuntan. Simposium Nasional Akuntansi Vokasi 2015 Menado.

Kafle, N. P. (2013). Hermeneutic phenomenological research method simplified. Bodhi: An Interdisciplinary Journal, 5(1), 181-200. https://doi.org/10.3126/bodhi.v5i1.8053

Lee, H. Y. (2008). A Comparative Study of Korean, Chinese, and Japanese Traditional Family and Contemporary Business Organizations.

Magfirah, S. (2016). Siri' Na Pacce dalam Suku Makassar Perspektif Al-Qur'an dan Hadis. $7(2), 158-170$.

Nakagane, K. (2017). China's Economic Development and Sino-Japanese Economic Relationships: Beyond the Flying Geese Pattern Theory. Journal of Contemporary East Asia Studies, 2(1), 29-54. https://doi.org/10.1080/24761028.2013.11869056

Rahayu, S., Suhaeb, F., Sulkarnain, Anrisal, \& Satnawati. (2018). Siri ' Na Pacce Culture of Bugis-Makassar in the Context of Modern Life ( Overview Historicality and Theory Jean Baudrillard Simulation ). International Journal of Management and Applied Science,ISSN :2394-7926, 4(7), 62-65.

Riana, I. G. (2013). Dampak Penerapan Kultur Lokal Tri Hita Karana terhadap Orientasi Kewirausahaan dan Orientasi Pasar. Jurnal Teknik Industri, 13(1). https://doi.org/10.9744/jti.13.1.37-44

Said, N. (2004). Religion and Cultural Identity Among the Bugis. Inter-Religio, 45, $12-$ 20.

Storper, M. (2009). Clark University. Economic Geography, 85(1), 1-21. https://doi.org/10.1126/science.11.277.620

Umiarso, H. H. (2011). Pendekatan Hermeneutik dalam Menghidupkan Tuhan: Sebuah Bunga Rampai. Yogyakarta: Ar Ruzz Media.

Wen-Cheng, W., Chien-Hung, L., \& Ying-Chien, C. (2011). Types of Competitive Advantage and Analysis. International Journal of Business and Management, 6(5), 100-104. https://doi.org/10.5539/ijbm.v6n5p100 